\title{
THE KNOWLEDGE OF SOCIAL WORKERS IN PRIVATE PRACTICE REGARDING HUMAN SEXUALITY AND SEX THERAPY
}

\author{
E Craig \\ University of Pretoria \\ MSE du Preez \\ University of Pretoria
}

\begin{abstract}
Sexual problems or dysfunctions remain one of the prominent reasons for marital and relationship problems. Sexuality is, however, only one of many components of a marriage or of a committed relationship. Relationship problems and sexual problems are often interlinked. The fact that sexual problems are often only symptoms of deeper relationship issues makes the social worker the ideal person to treat these sexual problems from a holistic perspective and within a relationship context. The nature of this research study thus evolved from the presumed lack of knowledge of social workers in private practice, and who specialise in couples therapy, regarding human sexuality and sex therapy. A qualitative research approach is used and applied research was conducted. An exploratory research design is utilised and a selfconstructed, mailed questionnaire was used as method of data collection. This research study found that the respondents answered only $58.53 \%$ of the knowledge-based questions correctly, thereby confirming their suspected lack of knowledge regarding human sexuality and sex therapy. The research results indicated a need for specialised education and training of social workers in the field of human sexuality and sex therapy.
\end{abstract}

\section{INTRODUCTION}

Sexual problems or dysfunctions remain one of the prominent reasons for marital and relationship problems (Fourie, 1984:23). Sexuality is, however, only one of the many components of a marriage or of a committed relationship. Relationship problems and sexual problems or dysfunctions are often interlinked. Woody (1992:5) states that people with sexual and intimacy problems seek help in various service settings. Those who know they are experiencing a sexual problem may seek help from a sex therapist. Clients with other forms of sexual distress might, however, see a marriage or relationship therapist. Woody (1992:6) states that "...sadly, some clients never articulate their sexual concerns or dilemmas because of the practitioner's lack of knowledge and skills". Weeks and Hof (1987:viii) also state that many sex therapists still remain focused on treating the sexual dysfunction, even though they recognise on some level of consciousness that sex is only a part of a particular couple's relationship.

It is often the case that a sexual problem is only a symptom of a relationship or marital problem, and this fact makes the social worker an ideal person to deal with the problem, as he or she is well trained in the dynamics of marriage and relationship therapy. The problem, however, is that social workers are often not adequately trained in the field of human sexuality and sex therapy, and they are therefore often unsure of their role within the multi-disciplinary team. Social workers are also often unaware that they actually do have the knowledge and skills to deal effectively with sexual problems and dysfunctions within the relationship context. "Some marital therapists may not be aware that after months of treatment, or even after termination, the couple had a sexual dysfunction. Often clients and therapists seem to have a collusive taboo against dealing with sexual problems" (Weeks \& Hof, 1987:ix). Clients with sexual problems or dysfunctions are often 
sent from therapist to therapist without being treated effectively. This is very disturbing for clients and has an important influence on client motivation and prognosis.

This emphasises the importance of formal education and training of social workers in the field of human sexuality and sex therapy to develop a more positive attitude towards sexuality. It is also important to raise the comfort level of the social worker regarding sexual issues. The social worker should also be able to identify sexual problems and dysfunctions by asking the appropriate questions and then to be able to refer clients where necessary to the appropriate specialists in the field.

As far back as 1975 the World Health Organisation, Technical Report (1975:50) had stressed the need for social workers to receive training in dealing with human sexuality. The report goes further by stating that, in order to develop a better understanding of the problems of human sexuality, it is necessary for social workers to develop healthy attitudes toward sexuality, marriage and contraception. An understanding by the worker of his or her own sexuality and a rational approach to his or her own sexual problems will help him or her to be able to deal better with the problems of others. More recently, the document Promotion of Sexual Health: Recommendations for Action (2000:31) stated that basic sexual health education for all health professionals should be included in their basic training as well as in continued educational programmes. Health professionals, according to this document, include the medical fraternity, nurses, clinical psychologists, social workers and general health practitioners. According to the Promotion of Sexual Health: Recommendations for Action (2000:43), this basic training should include the following:

- Basic knowledge of human sexuality;

- Awareness of personal attitudes toward one's own sexuality and that of others, which should include a respectful attitude toward persons with different sexual orientations and sexual practices;

- Basic skills in identifying clients with sexual difficulties and, if necessary, referring these clients to the appropriate specialised professional.

\section{AIMS AND OBJECTIVES}

The aim of this study was to explore and describe the knowledge of social workers in private practice, specialising in marriage and relationship therapy (couples therapy), with regards to human sexuality and sex therapy. To reach the above-mentioned aim, the following objectives were identified:

- To explore and describe, through a literature study, the nature, status and characteristics of human sexuality and sex therapy from a theoretical point of reference;

- To explore the role of sex therapy in couples therapy from a theoretical point of reference and within the social work context;

- To determine the level of knowledge of the social worker in private practice, specialising in couples therapy, with regards to human sexuality and sex therapy;

- To make recommendations to address the shortcomings of social workers' knowledge regarding human sexuality and sex therapy, identified by means of this study. 


\section{CONCEPTUALISATION}

Sex therapy is multi-dimensional in nature and sex therapists originate from various professional fields such as social work, psychology and the medical fraternity. Sex therapy has been used professionally since the $1960 \mathrm{~s}$, but obtained mainstream recognition with the publications of Masters and Johnson (1966). Since the 1960s sex therapy has become a major specialisation within the fields of psychology, psychiatry and medicine (Lopiccolo, 1978:ix). This view is shared by Weeks and Hof (1987:viii), who conclude that sex therapy shifted from being considered as an approach to an individual problem, to one where it is understood to be addressing a couples problem and even a family problem, thereby becoming part of marital and couples therapy. Taking into account the fact that sex is not only important at an individual, personal level, but also socially and politically, Bancroft (1989:1) emphasises the importance of effective sex therapy in couples therapy.

Although the short-term, behaviourally oriented approach to the treatment of sexual dysfunction has proven to be an effective treatment modality, couples who experience severe marital or relationship distress demonstrate a poorer prognosis for treatment in a variety of forms of sex therapy. The research that supports this notion is listed in Berg and Snyder (1981) and confirms the belief that sexual dysfunctions do not occur in a vacuum and that they must be viewed within the context of the total system of the client. This being the case, it is obvious that a comprehensive and multi-dimensional approach to the treatment of sexual dysfunctions must include a thorough evaluation of the couple's relationship. Weeks and Hof (1987:xiii-xiv) confirm this view: "The integration of sex therapy and couple therapy changes the way problems are understood from an individual to a systems perspective. This type of integration calls for a new breed of sex therapists. Therapists trained in individual, sex, couple and family therapy".

\section{RESEARCH METHODOLOGY}

A qualitative research approach was used and applied research was conducted. An exploratory research design was utilised, as there is little information about the knowledge of social workers with regards to human sexuality and sex therapy. A self-constructed, mailed questionnaire was used as method of data collection. A pilot study was conducted to determine the feasibility of the study and to pre-test the self-constructed questionnaire. An extensive literature study was undertaken and various experts in the field of research and sexology were consulted.

The South African Association of Social workers in Private Practice (SAASWIPP) offered a suitable resource (database) for the execution of the research. All social workers in private practice, with their specific area of speciality, are registered with SAASWIPP. SAASWIPP published a resource book in 2000 which lists all the social workers in private practice, with their specific specialisation. This resource book offered a set sampling frame, which improved the practical feasibility of the study. Mailed questionnaires were utilised to collect the data. It was therefore not necessary to make use of another sampling method such as cluster sampling to narrow respondents down to a certain geographical area.

The research population thus consisted of all social workers who are registered with The South African Association of Social Workers in Private Practice (SAASWIPP), as social workers in private practice, who specialise in couples therapy. They amounted to a total of 344 . A questionnaire was mailed to these 344 respondents. Forty-three of these questionnaires were returned unopened because the addresses have changed. It is thus evident that SAASWIPP's database was unfortunately not up to date. Of the 301 questionnaires that were delivered, 69 were returned. The total response rate was $23 \%$. The low response rate could be an indication that many 
respondents view the subject of sexuality as threatening, or that they declined to complete a questionnaire which may indicate their possible lack of knowledge of the subject. According to Bless and Higson-Smith (1995:112), however, the response rate of a mailed questionnaire is only between $20 \%$ and $40 \%$.

\section{EMPIRICAL RESULTS}

Ninety-three percent of respondents were female, while only $7 \%$ were male. The age of respondents varied between 30 and 74 years and the average age of respondents was 48.32 years at the time of the survey. The majority $(69 \%)$ of respondents were married at the time of the study, while $14 \%$ were divorced. The year in which respondents obtained their first degree stretched from 1948 to 1997, the largest percentage (76.9\%) of these being obtained between 1965 and 1991. The highest percentage $(47 \%)$ of respondents had a four-year bachelors degree in social work, while $37 \%$ hold a masters degree and $9 \%$ a doctoral degree. Only $7 \%$ of respondents hold a 3 -year social work degree. A high percentage $(76.78 \%$ ) of respondents completed other educational or training courses related to marriage/relationship and sex therapy. Most of these additional training courses, however, were short 2-3 day courses.

The number of years of social work experience of respondents ranged from 6 years to 48 years. The majority $(73.13 \%)$ of respondents have between 10 and 25 years social work experience; $74.24 \%$ of respondents had between 3 and 10 years experience as a social worker in private practice. The majority of respondents $(47.76 \%)$ were English speaking, while $38.81 \%$ of respondents were Afrikaans speaking and $13.43 \%$ spoke other languages. Eighty-five percent of respondents were white, $12 \%$ black and 3\% Indian. The largest number $(74.63 \%)$ of respondents were Protestant, $7.46 \%$ Roman Catholic and $8.96 \%$ Jewish.

The majority of respondents $(80.88 \%)$ indicated that they are able to refer clients to specialists in the field of sex therapy. Ninety-six percent of respondents indicated a need for social workers to be trained in human sexuality and sex therapy. Many respondents were of the opinion that this training should be included on undergraduate as well as postgraduate level.

The most frequent sexual problems presented by clients were lack of desire disorder $(51 \%)$ and libido differences (51\%) (refer Figure 1). Other sexual problems, i.e. anorgasmia, premature ejaculation, erectile dysfunction and painful intercourse were presented more seldom. The number of respondents for each problem is indicated by $\mathrm{N}$ in the figure.

Most of the respondents regarded themselves as being comfortable in discussing sexual problems with clients openly. The majority of respondents $(35 \%)$ received their primary sex education from peers, while $33 \%$ received it from their mother. Literature and books were also prevalent, with $22 \%$ listing these sources.

The majority of respondents $(52.38 \%)$ were of the opinion that they occasionally see clients that are in need of sex therapy, while $22.22 \%$ were of the opinion that they frequently see clients in need of sex therapy. Respondents $(56.52 \%)$ who occasionally take a complete sexual history from clients, while $26.09 \%$ of respondents never or rarely ever take a sexual history. Only $17.4 \%$ of respondents frequently take a sexual history from clients.

An average of $58.53 \%$ of respondents answered the knowledge-based questions correctly. A large percentage of respondents however declined to answer some of the questions. Ninety-six percent of the respondents were of the opinion that there exists a need for social workers to be trained in human sexuality and sex therapy. 
FIGURE 1

FREQUENCY OF SEXUAL PROBLEMS PRESENTED IN RESPONDENT'S PRACTICES

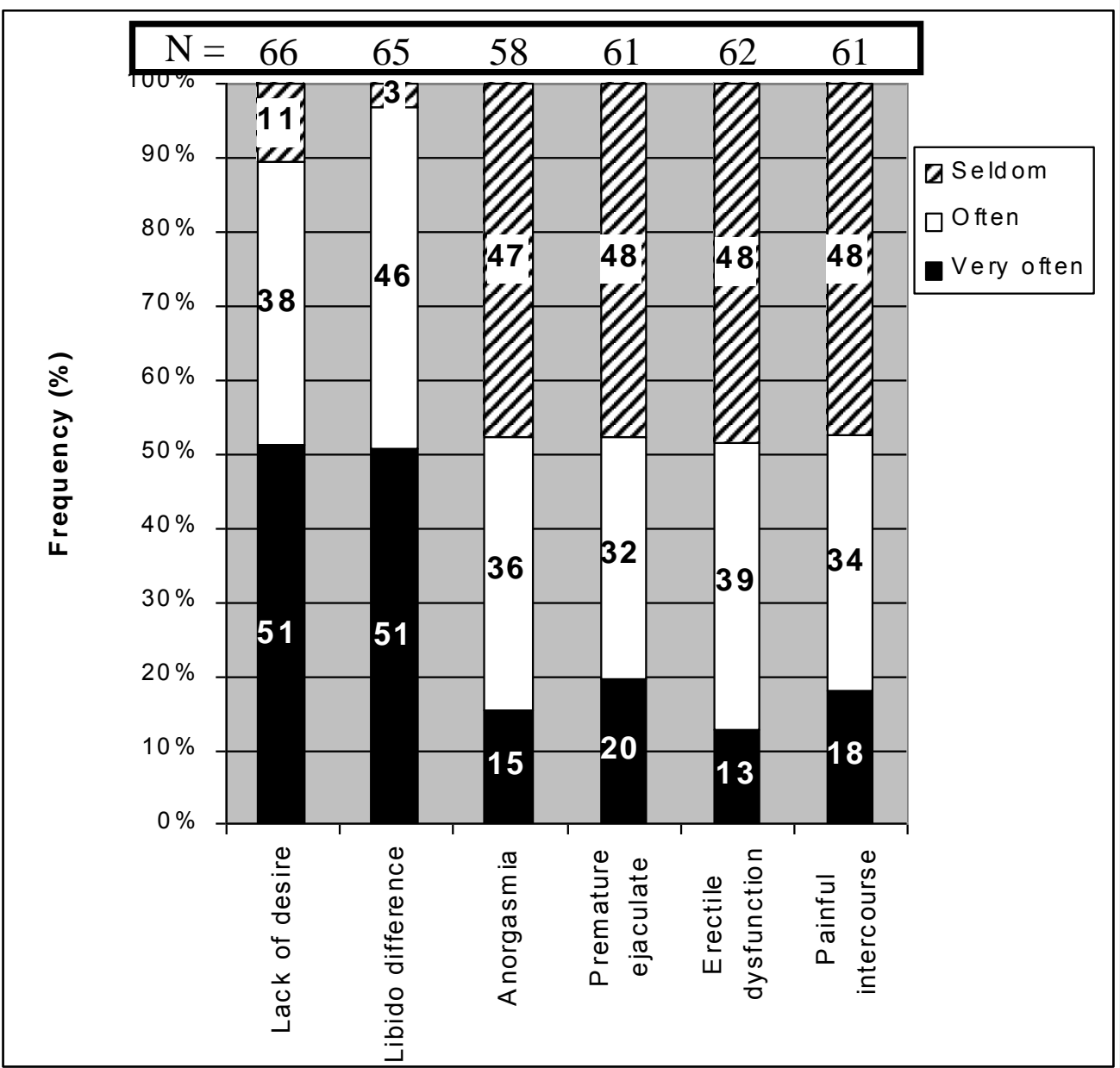

The knowledge questions are summarised in Figure 2, where the statistics of the knowledge-based questions (refer Appendix) are depicted. The correct answer is shown in each case. 
FIGURE 2

STATISTICS OF NUMBER OF CORRECT, INCORRECT AND UNSURE ANSWERS TO DESCRIBE KNOWLEDGE QUESTIONS

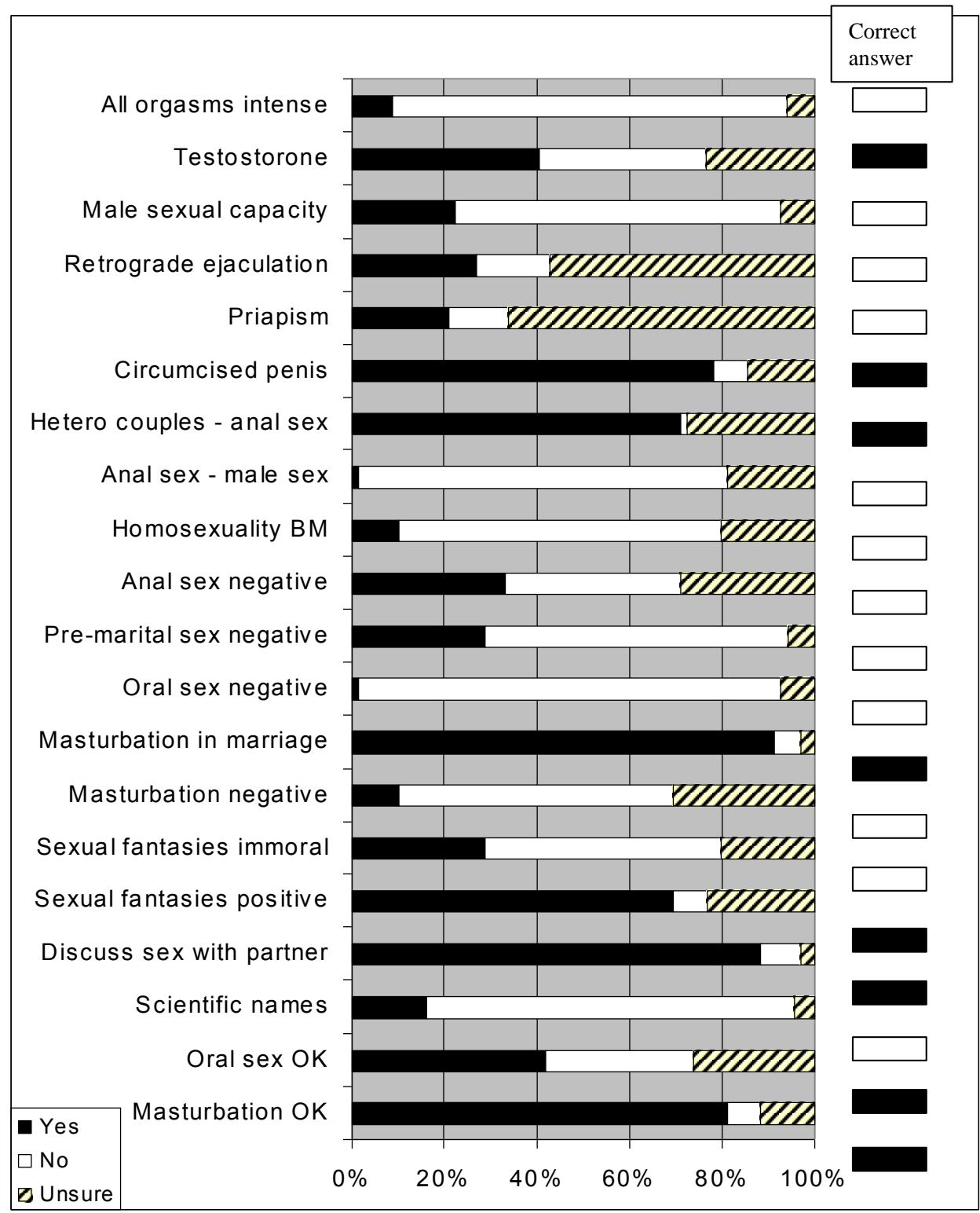




\section{APPENDIX: KNOWLEDGE-BASED QUESTIONS}

1. All orgasms are intense, explosive events.

2. The most important hormone in sexual motivation in males and females is testosterone.

3. Males have a greater sexual capacity than females.

4. Retrograde ejaculation means delayed ejaculation.

5. Priapism is an ability of some men to attain erections frequently and with minimum stimulation.

6. Functionally speaking the circumcised penis does not have a foreskin to retract during coitus or masturbation as the uncircumcised penis has.

7. There are some heterosexual couples who enjoy the practise of anal sex.

8. Anal sex is only practised during male sex.

9. Homosexuality can effectively be reversed by behavioural modification.

10. Anal sex is painful and leads to HIV infection.

11. Pre-marital sex is harmful and should be avoided.

12. Masturbation is sometimes an effective alternative to penetrative sex within a marriage or relationship.

13. Masturbation practised too frequently causes fatigue and physical debilitation.

14. Sexual fantasies can lead to immoral behaviour.

15. Sexual fantasies are a powerful aphrodisiac because they offer people a chance to enjoy sexual activities they might not normally - or necessarily ever - want to experience.

16. It is possible to discuss sexual related matters with my partner.

17. It is difficult to refer to the various parts of the genitals by their scientific names when discussing sexually-related issues with clients.

18. Oral sex is something that the majority of sexually active people engage in.

19. Masturbation offers a satisfactory outlet at all ages for the release of sexual tension. 


\section{CONCLUSIONS}

Conclusions from the empirical research findings, which are to a large extent supported by findings of a literature study (Craig, 2002), are the following:

- The male to female ratio indicated in this study correlates with the male to female ratio of social workers countrywide;

- Social workers in private practice, specialising in couples therapy, are mainly white, Afrikaans or English speaking and from a Protestant background;

- A large percentage of social workers in private practice are of middle age (between 40 and 50 years). This could indicate more life experience as well as more professional experience;

- The majority of social workers in private practice as indicated in this study are married, which may improve their credibility as therapists in providing effective sex therapy;

- The largest percentage $(76.78 \%)$ of respondents indicated that they obtained additional training. This may lead to the conclusion that there is a need for additional training of social workers in the field of human sexuality and sex therapy, and that social workers are open to continuing professional development. The majority of these additional training courses were short courses. It should be stressed, however, that practical implementation and the development of skills related to sex therapy should also be included in training;

- The level of knowledge of respondents correlates with the number of years of social work experience they have;

Social workers in private practise specialising in couples therapy do lack knowledge regarding human sexuality and sex therapy.

Other conclusions from the survey, again supported by findings of Craig (2002), are the following:

- There is an interaction between sexual difficulties and relationship problems;

- Relationship problems and sexual problems or dysfunctions are often interlinked;

- Sexual dysfunctions do not occur in a vacuum and must be viewed within the context of the total system of the client;

- Because of the interaction between relationship problems and sexual problems, the social worker is the ideal person to deal with sexual difficulties, as he or she is well trained in the dynamics of marriage and relationship therapy;

- There is a need for specialised education and training of social workers in the field of human sexuality and sex therapy;

- Social workers treating sexual difficulties should consult with a network of other related professionals (like the general physician, the gynaecologist and the urologist), where necessary. This will also simplify the therapeutic process and it would enable future researchers to utilise the multi-professional approach to sexual difficulties, where appropriate;

- The problem that was researched by means of this study, namely, the presumed lack of knowledge of social workers specialising in marriage and relationship therapy (couples 
therapy), with regards to human sexuality and sex therapy, is current and valuable to ensure that the social work profession keeps up to date with the worldwide movement to combine sex therapy with couples therapy;

- A more complex, integrative, holistic and post-modern approach to therapy for sexual difficulties has emerged;

- The purpose of sexual health care should be the enhancement of life and personal relationships and not merely counselling and care related to procreation and physical problems;

- A social work perspective on sexual health can be described as the enhancement or restoration of optimal sexual functioning within a relationship context.

\section{RECOMMENDATIONS}

The following recommendations can be made:

- Future research can focus more specifically on the comfort level of respondents regarding specific sex-related issues, as well as on general myths regarding sexuality that are still widely accepted as facts;

- Future research studies could also focus more on homosexual couples and on the exploration of their specific needs relating to relationship and sex therapy;

- Future studies can be extended to all registered social workers. It would also then be possible to draw interesting and insightful correlations between the knowledge of social workers within a structured career environment, and between social workers in private practice;

- Social workers should be educated to apply the worldwide trend of integrating sex therapy and relationship therapy in their work with couples who experience relationship and/or sexual difficulties, and the social workers should adopt a holistic approach;

- Future studies could focus more on the different cultural norms and values regarding human sexuality within the South African context;

- A therapist counselling clients with sexual difficulties should always take a complete medical and sexual history from the client;

- It is important for social workers to have sufficient knowledge regarding human sexuality and sex therapy because of the high incidence of sexual dysfunctions and difficulties in society;

- Sex therapy should be a systemic, well-planned and integrated therapeutic approach;

- Knowledge and skills lead to a positive and comfortable approach to human sexuality, which is of the utmost importance to provide a secure and comfortable environment in which clients can discuss possible sexual difficulties. The more knowledge social workers thus have, the better their comfort level would be to discuss sex-related issues with clients openly and non-judgementally;

- Training in human sexuality and sex therapy should be included in the undergraduate, postgraduate and continuing education levels of social work training; 
- This training should include desensitisation, the improvement of comfort levels regarding the subject of sexuality, as well as intensive practical and skills training;

- Future research studies can aid in the development of a course in human sexuality and sex therapy aimed at social workers specifically, as no such course exists at present;

- The field of social work can gain much in providing a commonly accepted, standardised and peer-reviewed course in human sexuality and sex therapy;

- Such a course should be accredited with the South African Qualifications Authority (SAQA), and should ideally be recognised internationally to optimise the value of such a course.

\section{REFERENCES}

BANCROFT, J. 1989. Human sexuality and its problems. Edinburgh: Churchill Livingston.

BERG, P. \& SNYDER, D.K. 1981. Differential diagnosis of marital and sexual distress: a multidimensional approach. Journal of Sex and Marital Therapy, 7: 290-295.

BLESS, C. \& HIGSON-SMITH, C. 1995. Fundamentals of social research methods: An African perspective $\left(2^{\text {nd }}\right.$ ed). Lusaka: Juta \& Co. Ltd.

CRAIG, E. 2002. The knowledge of social workers in private practice regarding human sexuality and sex therapy. Pretoria: University of Pretoria. (Unpublished MA dissertation)

FOURIE, M.C. 1984. The training of sex therapists in South Africa. Durban: University of Durban-Westville. (Unpublished DEd thesis)

LOPICCOLO, J. 1978. Handbook of sex therapy. New York: Plenum Press.

MASTERS, W.H. \& JOHNSON, V.E. 1966. Human sexual response. Boston: Little, Brown and Company.

PROMOTION OF SEXUAL HEALTH: RECOMMENDATIONS FOR ACTION. 2000. Regional consultation convened by the Pan American Health Organisation, World Health Organisation \& World Association for Sexology. 19-22 May, Antigua Gautemala, Guatemala.

WEEKS, G.P. \& HOF, L. 1987. Integrating sex and marital therapy: a clinical guide. New York: Brunner/Mazel, Inc.

WOODY, J.D. 1992. Treating sexual distress: Integrative systems therapy. Newbury Park: Sage Publications.

WORLD HEALTH ORGANISATION. 1975. Education and treatment in human sexuality. Technical report series, No. 572. Geneva: Switzerland.

Ms E Craig is a social worker and sexologist in private practice and post-graduate student in the Department of Social Work, University of Pretoria, Pretoria, South Africa.

Professor MSE du Preez is Head of the Department of Social Work at the University of Pretoria, Pretoria, South Africa. 